\title{
ANTIGENS OF THE TYPE-1 FIMBRIAE OF SALMONELLAE AND OTHER ENTEROBACTERIA
}

\author{
J. P. Duguid AND I. CAMPBell \\ Department of Bacteriology, University of Dundee, and \\ Department of Brewing and Biochemistry, Heriot-Watt University, Edinburgh
}

FIMBRIAE are non-flagellar filamentous appendages present in most strains of many species of enterobacteria, including Escherichia coli (Duguid et al., 1955), Shigella flexneri (Duguid and Gillies, 1957), Klebsiella aerogenes (Duguid, 1959) and salmonellae (Duguid, Anderson and Campbell, 1966). They are classified into several types, the commonest of which, type 1, is distinguished by the mannose-sensitive haemagglutinating property it confers on the bacteria that bear it (Duguid, 1968).

Gillies and Duguid (1958) found that the type-1 fimbriae of E. coli and Sh. flexneri contained heat-labile antigens that were distinct from the $O$ and other antigens present in non-fimbriate forms of the bacteria, and acted as dominant agglutinating antigens in reactions between fimbriate bacteria and homologous antisera. The fimbrial antigens were identical in all fimbriate strains of Sh. flexneri, and a minor fimbrial antigen was shared by Sh. flexneri and all type-1 fimbriate strains of $E$. coli. Different major fimbrial antigens were present in three groups of $E$. coli strains. Similar observations have been made by Cefalù (1960) and Grinberg (1967).

Gillies and Duguid found that the general properties of the fimbrial antigens differed from those of the cross-reacting alpha- and beta-antigens of enterobacteria described by Stamp and Stone (1944) and Mushin (1949), but resembled those of the " X-antigen " found by Topley and Ayrton (1924), Happold $(1928,1929)$ and Cruickshank (1939) in the bacteria in aged $(>16 \mathrm{hr})$ broth cultures of many salmonellae. None of five fimbriate cultures of salmonellae was agglutinated by a fimbrial antiserum to Sh. flexneri, but it was considered that the X-antigens of salmonellae might be fimbrial antigens with different specificity from those of Sh. flexneri. Since cross-reacting fimbrial antigens may produce " false-positive" reactions in diagnostic agglutination tests, a knowledge of their properties and distribution is important. We have therefore made a further study of the fimbrial antigens of salmonellae and their relations with those of other enterobacteria.

The demonstration of the presence of fimbrial antigens in a salmonella organism and their role in serological agglutinations is facilitated by the fact that it is generally possible to obtain both fimbriate and non-fimbriate cultures of bacteria of the same serotype for use as vaccines for the production of fimbrial and non-fimbrial antisera, and as agglutinable bacterial suspensions in tests with these sera. A salmonella organism that is genotypically fimbriate $\left(\mathrm{fim}^{+}\right)$ gives cultures containing a large proportion of fimbriate bacteria only when it is grown for a long period, e.g., $24-48 \mathrm{hr}$, at $37^{\circ} \mathrm{C}$ in aerobic static broth. These cultures are described as being in the fimbriate phase. When grown under other conditions, e.g., in plain broth for only $6 \mathrm{hr}$, in glucose broth for $12 \mathrm{hr}$ or on agar plates for $24 \mathrm{hr}$, the $\mathrm{fim}^{+}$strains give non-fimbriate-phase cultures

Received 18 Apr. 1969; accepted 28 Apr. 1969.

J. MED. MICROBIOL.-VOL. 2 (1969) 
containing few, if any, fimbriate bacteria. We were thus able to obtain, for comparison, fimbriate-phase and non-fimbriate-phase bacteria of the same strain. In several serotypes, moreover, we had collected exceptional strains that were genotypically non-fimbriate $\left(\mathrm{fim}^{-}\right)$and were able to compare non-fimbriate $48-\mathrm{hr}$ broth cultures of them with fimbriate 48 -hr broth cultures of $\mathrm{fim}^{+}$strains of the same serotype.

Crude fimbrial antisera were raised by immunisation of rabbits with fimbriatephase cultures and were tested in parallel against comparable fimbriate and non-fimbriate bacteria of various strains of salmonellae. They were then absorbed with homologous non-fimbriate-phase or $\mathrm{fim}^{-}$bacteria to free them from all agglutinating antibodies other than those to the fimbrial antigens. The resulting pure fimbrial antisera were tested against fimbriate-phase bacteria of different organisms to demonstrate agglutination reactions that were wholly dependent on the presence of the fimbrial antibodies.

\section{MATERIALS AND METHODS}

\section{Strains}

Most of the salmonella strains were from the series examined for fimbriation by Duguid et al. (1966). The letter " $\mathrm{N}$ " is prefixed to numbers designating strains from the National Collection of Type Cultures and the letter " $S$ " to numbers designating those from other suppliers. Strain SL483, which was kindly supplied by Professor B. A. D. Stocker, was a non-flagellate mutant from a line of the $\mathrm{fim}^{+}$strain LT2 of Salmonella typhimurium. S7471N was a wild-type fim - strain of $S$. typhimurium of phage-type 1 and biotype 17 (Duguid et al., 1966); it had O-antigens 4,5,12, and $\mathrm{H}$-antigens $\mathrm{i}-1,2$. S7471F was a $\mathrm{fim}^{+}$line derived from S7471N by transduction with phage P22 propagated on strain LT2 and selection in aerobic

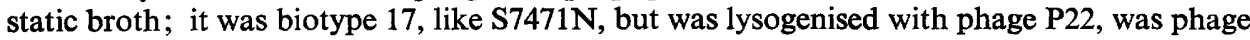
untypable, and probably contained a trace of $\mathrm{O}$-antigen 1 in addition to the antigens present in S7471N. The phage-types of strains were determined at the Enteric Reference Laboratory, Central Public Health Laboratory, London.

Strains of Shigella flexneri and Escherichia coli were from the series of Gillies and Duguid, strains of Klebsiella aerogenes and Enterobacter cloacae were from that of Duguid (1959) and strains of Citrobacter ballerupensis and C. freundii were from the National Collection of Type Cultures.

All the strains described as fimbriate had been shown to bear type-1 fimbriae by examination with the electron microscope and demonstration of mannose-sensitive haemagglutination. All those described as non-fimbriate had been found so in a series of broth cultures examined with the electron microscope and for haemagglutination. Strains N9499, N9621 and A3 of $K$. aerogenes formed thin type-3 fimbriae (Duguid, 1968) in addition to the thicker type-1 fimbriae. The O-, H- and $\mathrm{K}$-antigens of strains are given as identified for us in the Salmonella Reference Laboratory, Central Public Health Laboratory, London, or as notified by their supplier or as shown in the Kauffmann-White scheme (Edwards and Ewing, 1962, pp. 135-159).

\section{Culture media and methods}

Nutrient broth ( $p \mathrm{H} \mathrm{7 \cdot 3)}$ was Oxoid Lab-Lemco meat extract $1 \mathrm{~g}$, Oxoid bacteriological peptone $1 \mathrm{~g}, \mathrm{NaCl} 0.5 \mathrm{~g}$ and water $100 \mathrm{ml}$. Glucose broth was nutrient broth plus glucose $1 \mathrm{~g}$ per $100 \mathrm{ml}$. The broths were dispensed in 10 -ml volumes in test-tubes $(1.5 \times 15 \mathrm{~cm})$ stoppered with cotton-wool. Nutrient agar was nutrient broth plus 1 per cent. Davis New Zealand agar. Agar plates were $9-\mathrm{cm}$ petri dishes containing $c .15 \mathrm{ml}$ nutrient agar and were well dried before use.

Inoculation of broth was done either from a colony on a plate or, as during serial broth culture, with a loopful from the surface of a broth culture. Agar plates were inoculated 
heavily over the whole surface so that they produced confluent or nearly confluent growth. Incubation was aerobic and at $37^{\circ} \mathrm{C}$; its usual duration was $24 \mathrm{hr}$ for plates and $48 \mathrm{hr}$ for broths. Broths were not shaken or otherwise disturbed during incubation.

\section{Harvesting of cultures}

Broth cultures were mixed thoroughly to disperse any pellicle or deposit, and usually were killed by the addition of formaldehyde to a concentration of 0.25 per cent. The culture was then centrifuged at $1000 \mathrm{~g}$ for $30 \mathrm{~min}$., the supernatant broth was drained off for $c .5 \mathrm{~s}$ and the deposited bacteria were mixed with the small residuum of broth. This dense suspension is called the bacterial deposit. A small drop, about one-fifth of it, was taken for a haemagglutination test and the remainder was diluted to the required concentration in saline $(0.85$ per cent. $\mathrm{NaCl})$ or saline containing $0 \cdot 1$ per cent. formaldehyde.

Agar cultures were harvested into $10 \mathrm{ml}$ saline and were used alive or were killed by the addition of 0.25 per cent. formaldehyde. The suspension was centrifuged and the deposited bacteria were resuspended in saline or $0 \cdot 1$ per cent. formaldehyde-saline.

\section{Examination of cultures for degree of fimbriation}

All cultures were tested for haemagglutinating activity with a 2 per cent. (v/v) suspension of washed guinea-pig red blood cells by the method of Duguid et al. (1966). These authors had found that the strength of the reaction given by cultures of salmonellae provided an approximate indication of the degree of development of type- 1 fimbriae in them.

Haemagglutination tests. Two drops of red cells were mixed with a drop of bacterial deposit that had been centrifuged from a broth culture or from a suspension in saline of the bacteria from an agar culture. A strong reaction first becoming visible within $30 \mathrm{~s}$ indicated that the culture was richly enough fimbriated for it to be used in agglutination tests with fimbrial antisera. Such cultures were seen with the electron microscope to contain between 20 and 100 per cent. of fimbriate bacteria. The absence of haemagglutination in a test mixed for $30 \mathrm{~min}$. indicated that the culture was entirely non-fimbriate.

The haemagglutinating power $(H P)$ of a few cultures was measured by the method of Duguid and Gillies.

\section{Agglutinable bacterial suspensions}

The suspensions used in the agglutination tests consisted of $c .2 \times 10^{8}$ bacteria per ml. The bacteria used in most tests were stored at five times this concentration in $\mathbf{0 \cdot 1}$ per cent. formaldehyde-saline and were diluted five-fold in plain saline just before use.

Fimbriate-phase bacteria. Fim ${ }^{+}$strains were cultured serially in broths incubated for $48 \mathrm{hr}$ until a strongly haemagglutinating culture was obtained. This was usually the second or third in the series. The bacteria were centrifuged from the broth and suspended in $0 \cdot 1$ per cent. formaldehyde-saline. The suspensions of some cultures were auto-agglutinable, but those of most were stable and remained stable through several months' storage at $4^{\circ} \mathrm{C}$.

Non-fimbriate-phase bacteria. These were obtained by culture of $\mathrm{fim}^{+}$strains by three methods. (1) Culture in nutrient broth for $6 \mathrm{hr}$. A small amount of material from a colony was inoculated into a tube of broth and the tube was incubated for $6 \mathrm{hr}$. The bacteria, which then numbered 1-2 $\times 10^{8}$ per ml, were killed by the addition of $0 \cdot 25$ per cent. formaldehyde, centrifuged from the broth and suspended in 0.1 per cent. formaldehyde-saline. (2) Culture in glucose broth for $12 \mathrm{hr}$. A tube of 1 per cent. glucose broth was seeded from a colony and incubated for $12 \mathrm{hr}$. The culture was then several times denser than a $6-\mathrm{hr}$ culture and its $p \mathrm{H}$ was $c .5 \cdot 0$. The bacteria were killed with formaldehyde, deposited by centrifugation and resuspended in 0.1 per cent. formaldehyde-saline. (3) Culture on an agar plate for $24 \mathrm{hr}$. A nearly confluent culture was grown for $24 \mathrm{hr}$ on a well-dried agar plate from an inoculum of bacteria derived by serial culture on plates. The bacteria were harvested into plain saline or 0.25 per cent. formaldehyde-saline, separated from this saline by centrifugation and resuspended in saline or $\mathbf{0} \cdot 1$ per cent. formaldehyde-saline. 
The cultures were used to make non-fimbriate-phase suspensions after their centrifuged deposits had been shown to give negative or very weakly positive haemagglutination reactions $(\mathrm{HP}<25)$. Only the plate method was used to obtain non-fimbriate-phase cultures of Sh. flexneri, E. coli and $K$. aerogenes.

Genotypically non-fimbriate bacteria. Cultures of fim- $^{-}$strains were grown in nutrient broth for $\mathbf{4 8} \mathrm{hr}$ and the bacteria were harvested by the method used for fimbriate-phase bacteria.

Fimbriate bacteria deflagellated with acid. Flagella were removed with hydrochloric acid by Duncan's (1935) method. Live fimbriate-phase bacteria were centrifuged from $10 \mathrm{ml}$ of a 48-hr broth culture, washed once with saline and then suspended in $10 \mathrm{ml}$ fresh saline containing $0.005 \mathrm{~N}-\mathrm{HCl}$. The suspension was held at $37^{\circ} \mathrm{C}$ for $5 \mathrm{~min}$., after which sufficient $0.05 \mathrm{~N}-\mathrm{NaOH}$ was added to neutralise the acid. The bacteria were separated by centrifugation and suspended in $0 \cdot 1$ per cent. formaldehyde-saline.

Bacteria defimbriated and deflagellated with heat. Live fimbriate-phase bacteria from a 48-hr broth culture were suspended in $10 \mathrm{ml}$ plain saline and heated at $100^{\circ} \mathrm{C}$ for $30 \mathrm{~min}$. They were then deposited by centrifugation and suspended in 0.1 per cent. formaldehydesaline.

\section{Crude fimbrial antisera}

The immunising vaccines contained fimbriate-phase bacteria, c. $1.5 \times 10^{9}$ per $\mathrm{ml}$, in 0.25 per cent. formaldehyde-saline. Adult rabbits were given six injections of vaccine at intervals of 3 or 4 days. The first two doses were $0.5 \mathrm{ml}$ and given subcutaneously. The next two, also $0.5 \mathrm{ml}$, and the last two of $1.0 \mathrm{ml}$, were given intravenously. The animals were bled 10 days after the last injection. The serum was separated, and carefully clarified by centrifugation to remove blood cells, to which fimbriate bacteria might adhere. Sodium azide, 0.08 per cent., was added as preservative.

Crude non-fimbrial antisera were prepared similarly, but with vaccines made from cultures of $\mathrm{fim}^{-}$strains.

\section{Pure fimbrial antisera}

$\mathrm{O}$ - and $\mathrm{H}$-antibodies were removed from the crude fimbrial antiserum by absorption with live non-fimbriate-phase bacteria of the strain to which the serum had been raised. The absorbing bacteria were grown from non-fimbriate-phase inocula (1) by culture in glucose broth for $12 \mathrm{hr}$, and (2) by culture on agar plates for $24 \mathrm{hr}$. The two kinds of cultures were used in about equal proportions for the absorption of a serum. After they had been shown to be non-haemagglutinating, the bacteria were washed in saline, centrifuged and resuspended in fresh saline. Volumes of the final suspension were centrifuged to give a packed deposit of $c .10^{11}$ bacteria in each of a number of test-tubes. A volume of $5 \mathrm{ml}$ serum was mixed with a deposit, incubated with it for $1-2 \mathrm{hr}$ at $37^{\circ} \mathrm{C}$, separated from it by centrifugation and then mixed with a fresh deposit. Successive absorptions were done until a 1 in 25 dilution of the serum no longer agglutinated bacteria from glucose-broth and agar cultures of the absorbing strain. Care was taken to ensure that both $\mathrm{H}$-phases of biphasic salmonellae were adequately represented in the absorbing suspensions.

Some strains of salmonellae, e.g., S. typhimurium S7471F and $S$. newport S202, did not give non-fimbriate-phase cultures suitable for the absorptions. Their cultures grown in glucose broth were not sufficiently free from fimbriae and their plate cultures were too poorly flagellate to remove $\mathrm{H}$-antibodies in a convenient number of absorptions. The $\mathrm{H}$-antibodies were therefore removed from the sera to these strains by absorption with richly flagellate, non-fimbriate-phase cultures of a different strain. For example, the serum to $S$. typhimurium S7471F was absorbed with broth cultures of the genotypically non-fimbriate strain S7471N and that to $S$. newport $(6,8: \mathrm{e}, \mathrm{h}-1,2)$ with non-fimbriate-phase cultures of $S$. saintpaul $(1,4,5,12$ :e,h-1,2) grown in glucose broth. The O-antibodies were absorbed with nonfimbriate-phase agar cultures of the immunising strain. 


\section{Agglutination tests}

Volumes of $0.4 \mathrm{ml}$ of bacterial suspension were mixed with equal volumes of doubling dilutions of serum in narrow tubes. The lowest dilution of serum in a mixture with bacteria was 1 in 25 or, in some tests, 1 in 30 . A control tube contained saline in the place of diluted serum. The tests were incubated for $4 \mathrm{hr}$ at $37^{\circ} \mathrm{C}$ in a waterbath and then held overnight at c. $15^{\circ} \mathrm{C}$ or, when live bacteria were tested, at $4^{\circ} \mathrm{C}$. Before being read, each tube was briskly rotated to resuspend the bacterial sediment. It was viewed through a $\times 2$ magnifying lens while obliquely illuminated against a dark background. The titre recorded was the highest dilution of serum giving agglutination clearly visible through the lens.

\section{Absorption of fimbrial agglutinins}

Fimbriate bacteria of various strains were tested for their ability to absorb fimbrial agglutinins from pure fimbrial antisera to other strains. The absorbing bacteria were grown for $48 \mathrm{hr}$ in aerobic static broth, centrifuged from the broth and washed twice in saline. One millilitre of serum diluted to $7.5 \mathrm{ml}$ with saline was absorbed for $1-2 \mathrm{hr}$ at $37^{\circ} \mathrm{C}$ with a packed deposit of washed bacteria obtained from $100 \mathrm{ml}$ broth. Absorption was repeated once or twice until a 1 in 30 dilution of the serum failed to agglutinate fimbriate bacteria of the absorbing strain. The absorbed serum was then tested in doubling dilutions against fimbriate bacteria of the immunising strain and other strains.

\section{RESULTS}

\section{Demonstration of fimbrial agglutination}

Agglutinations dependent on the reaction of fimbrial antigens with fimbrial antibodies were demonstrated in two types of test. (1) Crude (unabsorbed) fimbrial antiserum to bacteria of one serotype was shown to agglutinate fimbriate-phase bacteria of other serotypes not sharing $\mathrm{O}-, \mathrm{H}-$, Vi- or $\mathrm{K}$ antigens with the first. (2) Pure fimbrial antiserum, from which O-, H- and other non-fimbrial agglutinins had been absorbed, was shown to agglutinate fimbriate-phase bacteria of homologous and heterologous serotypes. The results of typical experiments are shown in table $I$.

The granularity of the agglutinated fimbriate bacteria from cultures of salmonellae varied from moderately coarse to very fine. The finest reactions were visible only when the agglutinate was resuspended and viewed closely through a lens. The coarseness of the granules appeared to depend on the proportion of fimbriate bacteria in the culture, the number of fimbriae per bacterium and the length of the fimbriae. Reactions were detectable in most cultures containing more than 20 per cent. of fimbriate bacteria and having a haemagglutinating power (HP) greater than 100. Cultures of Shigella flexneri, Escherichia coli and Klebsiella aerogenes were generally more richly fimbriated than those of salmonellae, and thus gave coarser reactions.

Exposure to 0.1 or 0.25 per cent. formaldehyde in saline did not damage the fimbriae or alter their antigenic and haemagglutinating properties. The strength of the fimbrial agglutination reaction was as strong with bacteria that had been held in 0.1 per cent. formaldehyde for several days at $15-20^{\circ} \mathrm{C}$ or several months at $4^{\circ} \mathrm{C}$ as with fresh, live bacteria. For convenience, therefore, most of the tests were made with formaldehyde-killed bacteria.

The salmonellae for which results are reported (table II) were ones from 


\section{TABLe I}

Agglutination of Salmonella typhimurium, S. cubana and S. illinois bacteria in different states of fimbriation and flagellation by homologous- $H$, crude non-fimbrial, crude fimbrial and pure fimbrial antisera

\begin{tabular}{|c|c|c|c|c|c|c|c|c|c|}
\hline \multicolumn{5}{|c|}{ Bacteria tested for agglutination } & \multicolumn{5}{|c|}{$\begin{array}{l}\text { Agglutination titre in test of bacteria } \\
\text { with antiserum to: }\end{array}$} \\
\hline \multirow[b]{2}{*}{$\begin{array}{c}\text { Strain } \\
\text { (and H-phase) }\end{array}$} & \multirow[b]{2}{*}{$\begin{array}{l}\text { Method of culture } \\
\qquad\left(37^{\circ} \mathrm{C}\right)\end{array}$} & \multirow[b]{2}{*}{$\begin{array}{l}\text { Treat- } \\
\text { ment* }\end{array}$} & \multirow[b]{2}{*}{ Fimb- } & \multirow[b]{2}{*}{$\begin{array}{c}\text { Flag- } \\
\text { ella }\end{array}$} & \multirow{2}{*}{$\begin{array}{c}\text { homo- } \\
\text { logous } \\
\text { H- } \\
\text { phase† }\end{array}$} & \multicolumn{3}{|c|}{ S. typhimurium } & \multirow{2}{*}{$\begin{array}{c}S . \\
\text { cubana } \\
\text { N7101, } \\
\text { crude } \\
\text { fimbrial }\end{array}$} \\
\hline & & & & & & $\begin{array}{c}\text { S7471N, } \\
\text { crude } \\
\text { non- } \\
\text { fimbrial }\end{array}$ & $\begin{array}{c}\text { S7471F, } \\
\text { crude } \\
\text { fimbrial }\end{array}$ & $\begin{array}{c}\text { S7471F, } \\
\text { pure } \\
\text { fimbrial }\end{array}$ & \\
\hline $\begin{array}{l}\text { S. typhimurium } \\
\text { S7471N (1) }\end{array}$ & $\begin{array}{l}\text { Broth, } 48 \mathrm{hr} \\
\text { Broth, } 48 \mathrm{hr} \\
\text { Broth, } 48 \mathrm{hr}\end{array}$ & $\begin{array}{l}\text { Nil } \\
\text { Acid } \\
\text { Heat }\end{array}$ & $\bar{z}$ & $\frac{+}{-}$ & $\begin{array}{c}400 \S \\
\mathbf{N} \|\end{array}$ & $\begin{array}{r}51,200 \\
3200 \\
3200\end{array}$ & $\begin{array}{r}51,200 \\
6400 \\
6400\end{array}$ & $\begin{array}{l}\mathbf{N} \\
\mathbf{N} \\
\mathbf{N}\end{array}$ & $\begin{array}{l}\mathbf{N} \\
\mathbf{N} \\
\mathbf{N}\end{array}$ \\
\hline S7471F (1) $\ddagger$ & $\begin{array}{l}\text { Broth, } 48 \mathrm{hr} \\
\text { Broth, } 48 \mathrm{hr} \\
\text { Broth, } 48 \mathrm{hr} \\
\text { Broth, } 6 \mathrm{hr} \\
\text { Glucose broth, } 12 \mathrm{hr} \\
\text { Agar plate, } 24 \mathrm{hr}\end{array}$ & $\begin{array}{l}\text { Nil } \\
\text { Acid } \\
\text { Heat } \\
\text { Nil } \\
\text { Nil } \\
\text { Nil }\end{array}$ & $\begin{array}{l}+ \\
\pm \\
- \\
-\end{array}$ & $\begin{array}{l} \pm \\
\frac{+}{+} \\
\pm \\
+\end{array}$ & $\begin{array}{r}400 \\
N \\
N \\
400 \\
400 \\
N\end{array}$ & $\begin{array}{r}51,200 \\
3200 \\
3200 \\
51,200 \\
51,200 \\
3200\end{array}$ & $\begin{array}{r}51,200 \\
12,800 \\
6400 \\
25,600 \\
51,200 \\
6400\end{array}$ & $\begin{array}{r}3200 \\
3200 \\
\mathbf{N} \\
\mathbf{N} \\
\mathbf{N} \\
\mathbf{N}\end{array}$ & $\begin{array}{r}3200 \\
1600 \\
\mathbf{N} \\
\mathbf{N} \\
\mathbf{N} \\
\mathbf{N}\end{array}$ \\
\hline SLA83 $\left(f a^{-}\right)$ & $\begin{array}{l}\text { Broth, } 48 \mathrm{hr} \\
\text { Broth, } 6 \mathrm{hr}\end{array}$ & $\begin{array}{l}\text { Nil } \\
\text { Nil }\end{array}$ & \pm & - & $\begin{array}{l}\mathbf{N} \\
\mathbf{N}\end{array}$ & $\begin{array}{l}3200 \\
3200\end{array}$ & $\begin{array}{l}6400 \\
3200\end{array}$ & $\begin{array}{r}3200 \\
N\end{array}$ & $\begin{array}{r}1600 \\
N\end{array}$ \\
\hline $\begin{array}{l}\text { S. cubana } \\
\text { N7101 }\end{array}$ & $\begin{array}{l}\text { Broth, } 48 \mathrm{hr} \\
\text { Broth, } 48 \mathrm{hr} \\
\text { Broth, 48 hr } \\
\text { Broth, } 6 \mathrm{hr} \\
\text { Glucose broth, } 12 \mathrm{hr} \\
\text { Agar plate, } 24 \mathrm{hr}\end{array}$ & $\begin{array}{l}\text { Nil } \\
\text { Acid } \\
\text { Heat } \\
\text { Nil } \\
\text { Nil } \\
\text { Nil }\end{array}$ & $\begin{array}{l} \pm \\
\pm \\
\pm \\
-\end{array}$ & $\begin{array}{l} \pm \\
\pm \\
+ \\
+ \\
+\end{array}$ & $\begin{array}{r}400 \\
\mathbf{N} \\
\mathbf{N} \\
400 \\
400 \\
100\end{array}$ & $\begin{array}{l}\mathbf{N} \\
\mathbf{N} \\
25 \\
\mathbf{N} \\
\mathbf{N} \\
\mathbf{N}\end{array}$ & $\begin{array}{r}3200 \\
3200 \\
50 \\
N \\
N \\
50\end{array}$ & $\begin{array}{r}1600 \\
1600 \\
\mathbf{N} \\
\mathbf{N} \\
\mathbf{N} \\
\mathbf{N}\end{array}$ & $\begin{array}{r}6400 \\
6400 \\
800 \\
6400 \\
6400 \\
800\end{array}$ \\
\hline $\begin{array}{l}\text { S. illinois } \\
\text { N8498 (1) }\end{array}$ & $\begin{array}{l}\text { Broth, } 48 \mathrm{hr} \\
\text { Broth, } 48 \mathrm{hr} \\
\text { Broth, } 48 \mathrm{hr} \\
\text { Broth, } 6 \mathrm{hr} \\
\text { Glucose broth, } 12 \mathrm{hr} \\
\text { Agar plate, } 24 \mathrm{hr}\end{array}$ & $\begin{array}{l}\text { Nil } \\
\text { Acid } \\
\text { Heat } \\
\text { Nil } \\
\text { Nil } \\
\text { Nil }\end{array}$ & $\begin{array}{l}+ \\
\pm \\
\pm \\
- \\
-\end{array}$ & $\begin{array}{l} \pm \\
\pm \\
+ \\
\pm \\
-\end{array}$ & $\begin{array}{r}400 \\
N \\
N \\
400 \\
200 \\
N\end{array}$ & $\begin{array}{l}\mathbf{N} \\
\mathbf{N} \\
\mathbf{N} \\
\mathbf{N} \\
\mathbf{N} \\
\mathbf{N}\end{array}$ & $\begin{array}{r}6400 \\
6400 \\
\mathbf{N} \\
\mathbf{N} \\
\mathbf{N} \\
\mathbf{N}\end{array}$ & $\begin{array}{r}1600 \\
1600 \\
\mathbf{N} \\
\mathbf{N} \\
\mathbf{N} \\
\mathbf{N}\end{array}$ & $\begin{array}{r}1600 \\
1600 \\
\mathbf{N} \\
\mathbf{N} \\
\mathbf{N} \\
25\end{array}$ \\
\hline
\end{tabular}

* Nil. The bacteria were killed by the addition of formaldehyde immediately after being separated from the culture medium.

Acid. The bacteria were treated with $\mathrm{HCl}$ by Duncan's (1935) method before the addition of formaldehyde.

Heat. The bacteria were heated at $100^{\circ} \mathrm{C}$ for $30 \mathrm{~min}$. before the addition of formaldehyde.

† Standard absorbed H-phase-1 antiserum diluted to give homologous titre of 400 .

$\$$ Comparable results were obtained with H-phase-2 cultures of strains S7471N and S7471F. The crude antisera to these two strains contained H-phase-2 antibodies to about the same titres as the H-phase-1 antibodies.

$\S$ Titres in italics indicate tests giving heavy, coarsely granular agglutination; only finely granular agglutination was obtained in the other tests.

$\| \mathrm{N}=$ No agglutination in any dilution of serum. The lowest dilution tested was 1 in 25 . Flagellation, observed with the electron microscope, was poorly developed on agar plates, particularly in S. typhimurium and $S$. illinois. 


\section{TABLE II}

Agglutination reactions of fimbriate bacteria of 87 strains of 79 serotypes of salmonellae and 14 representative strains of other species of enterobacteria in tests with crude and pure fimbrial antisera to three salmonella serotypes

\begin{tabular}{|c|c|c|c|c|c|c|c|c|}
\hline \multicolumn{3}{|c|}{ Fimbriate bacteria tested for agglutination } & \multicolumn{6}{|c|}{$\begin{array}{l}\text { Reaction* of bacteria in test with } \\
\text { crude or pure fimbrial antiserum to: }\end{array}$} \\
\hline \multirow{2}{*}{$\begin{array}{l}\text { Serotype or species } \\
\text { (in order of } \\
\text { O-groups) }\end{array}$} & \multirow[t]{2}{*}{$\begin{array}{l}\mathrm{O}-\text { and } \mathrm{H} \text {-antigens } \\
(\mathrm{O}: \mathrm{H})\end{array}$} & \multirow[t]{2}{*}{$\begin{array}{l}\text { Strain } \\
\text { no. }\end{array}$} & \multicolumn{2}{|c|}{$\begin{array}{c}S . \\
\text { typhimurium } \\
\text { strain } \\
\text { S7471F }\end{array}$} & \multicolumn{2}{|c|}{$\begin{array}{l}\text { S. typhi } \\
\text { strain } \\
\text { N4446 }\end{array}$} & \multicolumn{2}{|c|}{$\begin{array}{l}\text { S. cubana } \\
\text { strain } \\
\text { N7101 }\end{array}$} \\
\hline & & & crude & pure & crude & pure & crude & pure \\
\hline $\begin{array}{l}\text { S. paratyphi } A \\
\text { S. paratyphi } A\end{array}$ & $\begin{array}{l}1,2,12: a- \\
1,2,12: a-\end{array}$ & $\begin{array}{l}\text { S25 } \\
\text { S2132 }\end{array}$ & $\dot{t}$ & + & $\begin{array}{l}\cdots \\
\cdots\end{array}$ & $\begin{array}{l}+ \\
\cdots\end{array}$ & + & $\begin{array}{l}\cdots \\
\cdots\end{array}$ \\
\hline $\begin{array}{l}\text { S. abony } \\
\text { S. abortusbovis } \\
\text { S. chester } \\
\text { S. derby } \\
\text { S. heidelberg } \\
\text { S. hessarek } \\
\text { S. kimuenza } \\
\text { S. kisangani } \\
\text { S. paratyphi B } \\
\text { S. paratyphi B } \\
\text { S. saintpaul } \\
\text { S. salinatis } \\
\text { S. stanley } \\
\text { S. typhimurium } \\
\text { S. typhimurium } \\
\text { S. typhimurium }\end{array}$ & $\begin{array}{l}\text { 1,4,5,12:b-e,n,x } \\
1,4,12,27: \mathrm{b}-\mathrm{e}, \mathrm{n}, \mathrm{x} \\
4,5,12 \mathrm{e}, \mathrm{h}-\mathrm{e}, \mathrm{n}, \mathrm{x} \\
1,4,5,12: \mathrm{f}, \mathrm{g}- \\
1,4,5,12: \mathrm{r}-1,2 \\
4,12,27: \mathrm{a}-1,5 \\
1,4,12,27: 1, \mathrm{v}-\mathrm{e}, \mathrm{n}, \mathrm{x} \\
1,4,5,12: \mathrm{a}-1,2 \\
1,4,5,12: \mathrm{b}-1,2 \\
1,4,5,12:-- \\
1,4,5,12: \mathrm{e}, \mathrm{h}-1,2 \\
4,12: \mathrm{d}, \mathrm{e}, \mathrm{h}-\mathrm{d}, \mathrm{e}, \mathrm{n}, \mathrm{z} 15 \\
4,5,12: \mathrm{d}-1,2 \\
(1), 4,5,12: \mathrm{i}-1,2 \\
1,4,5,12: \mathrm{i}-1,2 \\
4,5,12:-\mathrm{l}\end{array}$ & $\begin{array}{l}\text { N6017 } \\
\text { N5729 } \\
\text { N5719 } \\
\text { N5722 } \\
\text { S213 } \\
\text { S217 } \\
\text { N8268 } \\
\text { N7375 } \\
\text { N8390 } \\
\text { S543 } \\
\text { S209 } \\
\text { N6247 } \\
\text { S53 } \\
\text { S7471F } \\
\text { S206 } \\
\text { SL483 }\end{array}$ & $\begin{array}{l}\ldots . \\
\cdots \\
\ldots \\
\cdots \\
\cdots \\
\cdots \\
\cdots \\
\cdots \\
\cdots \\
\cdots \\
\cdots \\
\cdots \\
\cdots \\
\cdots\end{array}$ & $\begin{array}{l}+ \\
+ \\
\ldots \\
+ \\
+ \\
\ldots \\
+ \\
+ \\
+ \\
+ \\
+ \\
+ \\
+ \\
+ \\
+\end{array}$ & $\begin{array}{l}\ldots \\
\ldots \\
\ldots \\
\ldots \\
\ldots \\
\ldots \\
+ \\
+ \\
\ldots \\
+ \\
\ldots \\
\ldots \\
\ldots \\
\ldots\end{array}$ & $\begin{array}{l}\cdots \\
\cdots \\
\cdots \\
\cdots \\
+ \\
+ \\
+ \\
\cdots \\
+ \\
+ \\
+ \\
+ \\
+ \\
+ \\
+ \\
+\end{array}$ & $\begin{array}{l}\ldots \\
\ldots \\
+ \\
\cdots \\
\cdots \\
\ldots \\
+ \\
+ \\
\cdots \\
\ldots \\
\dddot{+} \\
\dddot{+} \\
\ddot{+}\end{array}$ & $\begin{array}{l}\cdots \\
\cdots \\
\cdots \\
\cdots \\
\cdots \\
\cdots \\
\cdots \\
\ldots \\
+ \\
\cdots \\
\cdots \\
\ldots \\
\cdots \\
\cdots\end{array}$ \\
\hline $\begin{array}{l}\text { S. bareilly } \\
\text { S. choleraesuis } \\
\text { S. choleraesuis } \\
\text { S. montevideo } \\
\text { S. montevideo } \\
\text { S. oranienburg } \\
\text { S. paratyphi C } \\
\text { S. potsdam } \\
\text { S. richmond } \\
\text { S. thompson }\end{array}$ & $\begin{array}{l}6,7: \mathrm{y}-1,5 \\
6,5:(\mathrm{c})-1,5 \\
6,7:(\mathrm{c})-1,5 \\
6,7: \mathrm{g}, \mathrm{m}, \mathrm{s}- \\
6,7: \mathrm{g}, \mathrm{m}, \mathrm{s}- \\
6,7: \mathrm{m}, \mathrm{t-} \\
6,7, \mathrm{Vi}: \mathrm{c}-1,5 \\
6,7: 1, \mathrm{ve}, \mathrm{n}, \mathrm{z}_{15} \\
6,7: \mathrm{y}-1,2 \\
6,7: \mathrm{k}-1,5\end{array}$ & $\begin{array}{l}\text { N5745 } \\
\text { N5738 } \\
\text { S215 } \\
\text { N5747 } \\
\text { S51 } \\
\text { S17 } \\
\text { N96 } \\
\text { S210 } \\
\text { S302 } \\
\text { S49 }\end{array}$ & $\begin{array}{l}\ldots \\
\ldots \\
\ldots \\
+ \\
+ \\
+ \\
\ldots \\
\ldots \\
\ldots\end{array}$ & $\begin{array}{l}+ \\
+ \\
+ \\
+ \\
+ \\
+ \\
\ddot{+} \\
\ddot{+} \\
\ddot{+}\end{array}$ & $\begin{array}{l}\dddot{\ldots} \\
+ \\
+ \\
+ \\
+ \\
+ \\
\ddot{+} \\
+ \\
+\end{array}$ & $\begin{array}{l}+ \\
+ \\
+ \\
+ \\
+ \\
\cdots \\
+ \\
+ \\
+ \\
\cdots\end{array}$ & $\begin{array}{l}+ \\
+ \\
+ \\
+ \\
+ \\
+ \\
\ddot{+} \\
\ddot{+}\end{array}$ & $\begin{array}{l}\ldots \\
\ldots \\
+ \\
\dddot{+} \\
\cdots \\
\ldots \\
\cdots \\
\cdots\end{array}$ \\
\hline $\begin{array}{l}\text { S. bovismorbificans } \\
\text { S. kentucky } \\
\text { S. muenchen } \\
\text { S. newport } \\
\text { S. virginia }\end{array}$ & $\begin{array}{l}6,8: \mathrm{r}-1,5 \\
(8), 20: \mathrm{i}-\mathrm{z}_{6} \\
68: \mathrm{d}-1,2 \\
6,8: \mathrm{e}, \mathrm{h}-1,2 \\
(8): \mathrm{d}-1,2\end{array}$ & $\begin{array}{l}\text { S216 } \\
\text { S894 } \\
\text { S214 } \\
\text { S202 } \\
\text { N6947 }\end{array}$ & $\begin{array}{l}\cdots \\
\cdots \\
\cdots \\
\cdots \\
\cdots\end{array}$ & $\begin{array}{l}\ldots \\
\dddot{+} \\
+ \\
+\end{array}$ & $\begin{array}{l}\dddot{y} \\
\dddot{+} \\
\cdots\end{array}$ & $\begin{array}{l}+ \\
\ldots \\
+ \\
+ \\
\cdots\end{array}$ & $\begin{array}{l}\dddot{t} \\
\dddot{t} \\
\cdots\end{array}$ & $\begin{array}{l}\ldots \\
\cdots \\
\cdots \\
\cdots\end{array}$ \\
\hline $\begin{array}{l}\text { S. alabama } \\
\text { S. dublin } \\
\text { S. enteritidis } \\
\text { S. enteritidis } \\
\text { S. haarlem } \\
\text { S. lomalinda } \\
\text { S. miami } \\
\text { S. moscow } \\
\text { S. strasbourg } \\
\text { S. typhi } \\
\text { S. typhi }\end{array}$ & $\begin{array}{l}\text { 9,12:c-e,n, } \mathrm{z}_{15} \\
\text { 1,9,12:g,p- } \\
1,9,12: \mathrm{g}, \mathrm{m}- \\
\text { 1,9,12:g,m- } \\
\text { (9),46:z-e,n,x } \\
\text { 9,12:a-e,n,x } \\
\text { 1,9,12:a-1,5 } \\
\text { 9,12:g,q- } \\
\text { (9),46:d-1,7 } \\
\text { 9,12,Vi:d- } \\
\text { 9,12,Vi:d- }\end{array}$ & $\begin{array}{l}\text { N9868 } \\
\text { S251 } \\
\text { N4444 } \\
\text { S204 } \\
\text { N9906 } \\
\text { N6704 } \\
\text { S1121 } \\
\text { N5768 } \\
\text { N9786 } \\
\text { N4446 } \\
\text { N6029 }\end{array}$ & $\begin{array}{l}\ldots \\
\ldots \\
\ldots \\
\dddot{+} \\
\ldots \\
\ldots \\
+ \\
\ldots \\
+ \\
+\end{array}$ & $\begin{array}{l}\ldots \\
\dddot{y} \\
+ \\
+ \\
+ \\
\dddot{+} \\
+ \\
+ \\
+ \\
+ \\
+\end{array}$ & $\begin{array}{l}\ldots \\
\cdots \\
\cdots \\
\cdots \\
\cdots \\
\cdots \\
\cdots \\
\cdots \\
\cdots \\
\end{array}$ & $\begin{array}{l}\cdots \\
\dddot{m} \\
+ \\
+ \\
\dddot{+} \\
\dddot{+} \\
+ \\
+ \\
+\end{array}$ & $\begin{array}{l}+ \\
+ \\
\cdots \\
\cdots \\
\cdots \\
\cdots \\
\cdots \\
+ \\
+ \\
+\end{array}$ & $\begin{array}{l}\ldots \\
\ldots \\
\ldots \\
\ldots \\
\ldots \\
\ldots \\
\ldots \\
\ldots \\
\ldots \\
+\ldots\end{array}$ \\
\hline
\end{tabular}


TABLE II (continued)

\begin{tabular}{|c|c|c|c|c|c|c|c|c|}
\hline \multicolumn{3}{|c|}{ Fimbriate bacteria tested for agglutination } & \multicolumn{6}{|c|}{$\begin{array}{l}\text { Reaction* of bacteria in test with } \\
\text { crude or pure fimbrial antiserum to: }\end{array}$} \\
\hline \multirow{2}{*}{$\begin{array}{l}\text { Serotype or species } \\
\text { (in order of } \\
\text { O-groups) }\end{array}$} & \multirow{2}{*}{$\begin{array}{l}\mathrm{O} \text { - and } \mathrm{H} \text {-antigens } \\
(\mathrm{O}: \mathrm{H})\end{array}$} & \multirow{2}{*}{$\begin{array}{l}\text { Strain } \\
\text { no. }\end{array}$} & \multicolumn{2}{|c|}{$\begin{array}{c}S . \\
\text { typhimurium } \\
\text { strain } \\
\text { S7471F }\end{array}$} & \multicolumn{2}{|c|}{$\begin{array}{l}\text { S. typhi } \\
\text { strain } \\
\text { N4446 }\end{array}$} & \multicolumn{2}{|c|}{$\begin{array}{l}S . \text { cubana } \\
\text { strain } \\
\text { N7101 }\end{array}$} \\
\hline & & & crude & pure & crude & pure & crude & pure \\
\hline $\begin{array}{l}\text { S. anatum } \\
\text { S. butantan } \\
\text { S. give } \\
\text { S. meleagridis } \\
\text { S. nyborg } \\
\text { S. orion }\end{array}$ & $\begin{array}{l}\text { 3,10:e,h-1,6 } \\
3,10: b-1,5 \\
3,10: 1, \mathrm{v}-1,7 \\
3,10: \mathrm{e}-1, \mathrm{w} \\
3,10: \mathrm{e} \text {, }-1,7 \\
3,10: y-1,5\end{array}$ & $\begin{array}{l}\text { S15 } \\
\text { S212 } \\
\text { S219 } \\
\text { N6023 } \\
\text { S1049 } \\
\text { S1045 }\end{array}$ & $\begin{array}{l}\cdots \\
\cdots \\
\ldots \\
\cdots \\
\cdots\end{array}$ & $\begin{array}{l}+ \\
+ \\
\ldots \\
+ \\
\cdots \\
\cdots\end{array}$ & $\begin{array}{l}+ \\
+ \\
+ \\
+ \\
+ \\
+\end{array}$ & $\begin{array}{l}+ \\
\cdots \\
+ \\
\cdots \\
\cdots \\
\cdots\end{array}$ & $\begin{array}{l}+ \\
+ \\
+ \\
\dddot{+} \\
+\end{array}$ & $\begin{array}{l}\ldots \\
\cdots \\
\cdots \\
\ldots \\
\cdots\end{array}$ \\
\hline $\begin{array}{l}\text { S. cambridge } \\
\text { S. tuebingen }\end{array}$ & $\begin{array}{l}3,15: \mathrm{e}, \mathrm{h}-1, \mathrm{w} \\
3,15: \mathrm{y}-1,2\end{array}$ & $\begin{array}{l}\text { S1048 } \\
\text { N9909 }\end{array}$ & + & $\begin{array}{l}\cdots \\
\cdots\end{array}$ & + & $\ldots$ & + & $\cdots$ \\
\hline S. illinois & (3),(15),34: $z_{10-1,5}$ & N8498 & $\ldots$ & + & + & $\ldots$ & + & + \\
\hline S. senftenberg & $1,3,19: \mathrm{g}, \mathrm{s}, \mathrm{t}-$ & N5788 & + & + & + & + & + & $\ldots$ \\
\hline $\begin{array}{l}\text { S. aberdeen } \\
\text { S. rubislaw }\end{array}$ & $\begin{array}{l}11: i-1,2 \\
11: r-e, n, x\end{array}$ & $\begin{array}{l}\text { S222 } \\
\text { S893 }\end{array}$ & $\dddot{+}$ & + & $\dddot{t}$ & + & $\begin{array}{l} \\
\cdots\end{array}$ & $\begin{array}{l}\cdots \\
\cdots\end{array}$ \\
\hline S. poona & $13,22: z-1,6$ & N5792 & $\cdots$ & + & $\cdots$ & + & $\cdots$ & $\cdots$ \\
\hline $\begin{array}{l}\text { S. cubana } \\
\text { S. wichita } \\
\text { S. worthington }\end{array}$ & $\begin{array}{l}1,13,23: z_{29-} \\
1,13,23: d- \\
1,13,23: z-1, w\end{array}$ & $\begin{array}{l}\text { N7101 } \\
\text { N6019 } \\
\text { S45 }\end{array}$ & $\begin{array}{l}+ \\
\cdots \\
\cdots\end{array}$ & $\begin{array}{l}+ \\
+ \\
\cdots\end{array}$ & $\begin{array}{l}+ \\
\dddot{+}\end{array}$ & $\begin{array}{l}+ \\
+ \\
+\end{array}$ & $\begin{array}{l}\ldots \\
\cdots \\
\cdots\end{array}$ & $\begin{array}{l}+ \\
\cdots \\
\cdots\end{array}$ \\
\hline $\begin{array}{l}\text { S. carrau } \\
\text { S. onderstepoort }\end{array}$ & $\begin{array}{l}6,14,24: y-1,7 \\
1,6,14,25: e, h-1,5\end{array}$ & $\begin{array}{l}\text { N5794 } \\
\text { N5795 }\end{array}$ & $\begin{array}{l}\cdots \\
\cdots\end{array}$ & + & $\dddot{+}$ & + & + & $\begin{array}{l}\ldots \\
\cdots\end{array}$ \\
\hline $\begin{array}{l}\text { S. hvittingfoss } \\
\text { S. vancouver }\end{array}$ & $\begin{array}{l}16: b-e, n, x \\
16: c-1,5\end{array}$ & $\begin{array}{l}\text { N5796 } \\
\text { N8460 }\end{array}$ & $\begin{array}{l}+ \\
\cdots\end{array}$ & $\begin{array}{l}+ \\
\cdots\end{array}$ & $\begin{array}{l}+ \\
\cdots\end{array}$ & + & + & + \\
\hline $\begin{array}{l}\text { S. bleadon } \\
\text { S. cerro }\end{array}$ & $\begin{array}{l}17:(f), g, t- \\
18: z_{4,}, z_{23^{-}}\end{array}$ & $\begin{array}{l}\text { N9604 } \\
\text { N5801 }\end{array}$ & + & $\dddot{+}$ & $\dot{t}$ & $\dddot{+}$ & $\stackrel{+}{+}$ & $\begin{array}{l}\cdots \\
\cdots\end{array}$ \\
\hline $\begin{array}{l}\text { S. minnesota } \\
\text { S. seattle } \\
\text { S. godesberg } \\
\text { S. adelaide } \\
\text { S. mgulani } \\
\text { S. wandsworth } \\
\text { S. degania }\end{array}$ & $\begin{array}{l}21: \mathrm{b}-\mathrm{e}, \mathrm{n}, \mathrm{x} \\
28: \mathrm{a}-\mathrm{e}, \mathrm{n}, \mathrm{x} \\
30: \mathrm{g}, \mathrm{m}- \\
35: \mathrm{f}, \mathrm{g}- \\
38: \mathrm{i}-1,2 \\
39: \mathrm{b}-1,2 \\
40: \mathrm{z}_{4}, \mathrm{z}_{24^{-}}\end{array}$ & $\begin{array}{l}\text { N5800 } \\
\text { N9914 } \\
\text { N9918 } \\
\text { N6586 } \\
\text { N8492 } \\
\text { S4026 } \\
\text { N9930 }\end{array}$ & $\begin{array}{l}+ \\
+ \\
+ \\
+ \\
\cdots \\
\cdots\end{array}$ & $\begin{array}{l}+ \\
\dddot{+} \\
+ \\
+ \\
+ \\
+ \\
+\end{array}$ & $\begin{array}{l}+ \\
+ \\
\cdots \\
+ \\
+ \\
\cdots\end{array}$ & $\begin{array}{l}+ \\
\dddot{+} \\
+ \\
+ \\
+ \\
+ \\
+\end{array}$ & $\begin{array}{l}+ \\
+ \\
+ \\
+ \\
+ \\
\dddot{+}\end{array}$ & $\begin{array}{l}\ldots \\
\cdots \\
\cdots \\
\cdots \\
\cdots \\
\cdots\end{array}$ \\
\hline S. waycross & $41: \mathrm{z}_{4}, \mathrm{z}_{23^{-}}$ & N7401 & + & + & + & + & + & $\ldots$ \\
\hline $\begin{array}{l}\text { S. berkeley } \\
\text { S. niarembe } \\
\text { S. deversoir } \\
\text { S. quinhon }\end{array}$ & $\begin{array}{l}43: a-1,5 \\
44: a-1, w \\
45: c-e, n, x \\
47: z_{44^{-}}\end{array}$ & $\begin{array}{l}\text { N8260 } \\
\text { N8279 } \\
\text { N9792 } \\
\text { N10076 }\end{array}$ & $\begin{array}{l}\cdots \\
\cdots \\
+ \\
+\end{array}$ & $\begin{array}{l}+ \\
+ \\
+\end{array}$ & $\begin{array}{l}+ \\
+ \\
+ \\
\cdots\end{array}$ & $\begin{array}{l}+ \\
+ \\
+ \\
+\end{array}$ & $\begin{array}{l}+ \\
+ \\
+ \\
+\end{array}$ & $\begin{array}{l}\ldots \\
\cdots \\
\cdots \\
\cdots\end{array}$ \\
\hline S. dahlem & $48: \mathrm{k}-\mathrm{e}, \mathrm{n}, \mathrm{z}_{15}$ & N9949 & + & + & $\cdots$ & $\ldots$ & + & $\cdots$ \\
\hline
\end{tabular}


TABLE II (continued)

Fimbriate bacteria tested for agglutination

\begin{tabular}{|c|c|c|c|c|c|c|c|c|}
\hline \multirow{2}{*}{$\begin{array}{l}\text { Serotype or species } \\
\text { (in order of } \\
\text { O-groups) }\end{array}$} & \multirow{2}{*}{$\begin{array}{c}\mathrm{O} \text { - and } \mathrm{H} \text {-antigens } \\
(\mathrm{O}: \mathrm{H})\end{array}$} & \multirow{2}{*}{$\begin{array}{c}\text { Strain } \\
\text { no. }\end{array}$} & \multicolumn{2}{|c|}{$\begin{array}{c}S . \\
\text { typhimurium } \\
\text { strain } \\
\text { S7471F }\end{array}$} & \multicolumn{2}{|c|}{$\begin{array}{l}\text { S. typhi } \\
\text { strain } \\
\text { N4446 }\end{array}$} & \multicolumn{2}{|c|}{$\begin{array}{l}\text { S. cubana } \\
\text { strain } \\
\text { N7101 }\end{array}$} \\
\hline & & & crude & pure & crude & pure & crude & pure \\
\hline $\begin{array}{l}\text { S. greenside } \\
\text { S. treforest } \\
\text { S. flottbek } \\
\text { S. humber }\end{array}$ & $\begin{array}{l}50: z-e, n, x \\
1,51: z-1,6 \\
52: b- \\
53: z_{4}, z_{24}\end{array}$ & $\begin{array}{l}\text { N9936 } \\
\text { N10075 } \\
\text { S4028 } \\
\text { N10078 }\end{array}$ & $\begin{array}{l}+ \\
\cdots \\
\cdots\end{array}$ & $\begin{array}{l}+ \\
+ \\
+ \\
+\end{array}$ & $\begin{array}{l}\dddot{x} \\
+ \\
+\end{array}$ & $\begin{array}{l}+ \\
+ \\
+ \\
+\end{array}$ & $\begin{array}{l}+ \\
+ \\
+ \\
+\end{array}$ & $\begin{array}{l}\cdots \\
\cdots \\
\cdots \\
\cdots\end{array}$ \\
\hline $\begin{array}{l}\text { S. uccle } \\
\text { Unnamed } \\
\text { S. locarno }\end{array}$ & $\begin{array}{l}54: \mathrm{g}, \mathrm{s,t}- \\
56: \mathrm{e}, \mathrm{n}, \mathrm{x}-1,7 \\
57: \mathrm{z}_{29}-\mathrm{Z}_{42}\end{array}$ & $\begin{array}{l}\text { N10251 } \\
\text { S4029 } \\
\text { N10272 }\end{array}$ & $\begin{array}{l}\cdots \\
\cdots \\
\cdots\end{array}$ & $\begin{array}{l}+ \\
+ \\
+\end{array}$ & $\begin{array}{l}+ \\
\dddot{+}\end{array}$ & $\begin{array}{l}+ \\
+ \\
+\end{array}$ & $\begin{array}{l}+ \\
\cdots \\
\cdots\end{array}$ & $\begin{array}{l}\cdots \\
\cdots \\
\cdots\end{array}$ \\
\hline S. luton & $60: z-e, n, x$ & N10346 & + & + & $\ldots$ & + & + & $\ldots$ \\
\hline $\begin{array}{l}\text { A. arizonae } \\
\text { A. arizonae }\end{array}$ & $\begin{array}{l}1,3: 1,3,11 \\
8: 1,7,8\end{array}$ & $\begin{array}{l}\text { N7296 } \\
\text { N7311 }\end{array}$ & + & + & + & + & + & $\ldots$ \\
\hline C. ballerupensis & $2: 3$ & N7829 & + & + & + & + & + & $\ldots$ \\
\hline C. freundii & $32: 1,5$ & N6269 & $\ldots$ & + & + & + & + & $\cdots$ \\
\hline Sh. flexneri & (type 1a) & N8192 & - & - & - & - & - & - \\
\hline $\begin{array}{l}\text { E. coli } \dagger \\
\text { E. coli } \\
\text { E. coli }\end{array}$ & $\begin{array}{l}\mathrm{O} 9: \mathrm{K}(\mathrm{A}) ?: \mathrm{H}- \\
\mathrm{O} 86: \mathrm{K} 61(\mathrm{~B} 7): \mathrm{H} ? \\
\mathrm{O} ?: \mathrm{H}-\end{array}$ & $\begin{array}{l}\text { A93 } \\
\text { A108 } \\
\text { A122 }\end{array}$ & $\begin{array}{l}- \\
- \\
-\end{array}$ & $\bar{z}$ & $\begin{array}{l}\overline{-} \\
\overline{-}\end{array}$ & $\overline{-}$ & $\begin{array}{l}- \\
-\end{array}$ & $\begin{array}{l}- \\
-\end{array}$ \\
\hline $\begin{array}{l}K . \text { aerogenes } \\
K . \text { aerogenes } \\
K . \text { aerogenes } \\
K . \text { aerogenes }\end{array}$ & $\begin{array}{l}\text { K1 } \\
\text { K2 } \\
\text { K54 } \\
\text { K55 }\end{array}$ & $\begin{array}{l}\text { N9499 } \\
\text { N9621 } \\
\text { A3 } \\
\text { K55 }\end{array}$ & $\begin{array}{l}- \\
- \\
-\end{array}$ & $\begin{array}{l}- \\
\overline{-} \\
-\end{array}$ & $\begin{array}{l}- \\
- \\
-\end{array}$ & $\begin{array}{l}- \\
- \\
-\end{array}$ & $\begin{array}{l}\bar{z} \\
\bar{z}\end{array}$ & $\begin{array}{l}- \\
- \\
-\end{array}$ \\
\hline $\begin{array}{l}\text { Ent. cloacae } \\
\text { Ent. cloacae }\end{array}$ & $\begin{array}{l}\cdots \\
\cdots\end{array}$ & $\begin{array}{l}\text { C035 } \\
\text { C793 }\end{array}$ & $\overline{-}$ & $\overline{-}$ & 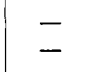 & - & - & $\overline{-}$ \\
\hline
\end{tabular}

Reaction* of bacteria in test with crude or pure fimbrial antiserum to:

* Reactions. $-=$ Serum did not agglutinate fimbriate-phase bacteria $+=$ crude fimbrial antiserum agglutinated fimbriate-phase bacteria to a high titre $(400-12,800)$, but did not agglutinate non-fimbriate-phase bacteria of the same strain (or, in a few tests, did so only to low titre, 25-100); or $+=$ pure fimbrial antiserum agglutinated fimbriate-phase bacteria to a moderate or high titre $(200-12,800) . \quad \ldots=$ Not tested.

$\dagger$ Antigens. $\mathrm{O}$ ?, $\mathrm{K}(\mathrm{A})$ ? and $\mathrm{H}$ ? = Antigen present but unidentified. -- or $\mathrm{H}-=$ Non-flagellate strain.

which we succeeded in obtaining a stable, adequately fimbriated culture for use in the agglutination tests. Only about two-thirds of the strains examined gave such a culture, which was usually the second or third of a series of broth cultures incubated for periods of $48 \mathrm{hr}$. Other strains gave only cultures that were unsuitable for the tests, either because they were too poorly fimbriated or because they were auto-agglutinable in saline. 
Deficient fimbriation. Strains remaining poorly fimbriated on repeated subculture in broth were recognised by their weak haemagglutination reactions and were discarded. The cultures selected as suitable for the tests on the basis of their strong haemagglutinating activity were subjected to control tests with a cross-reacting fimbrial antiserum to confirm that they were susceptible to agglutination by fimbrial antibody. This confirmation was necessary in the case of cultures that were to be used in tests demonstrating the absence of crossreactivity with a heterologous serum. For instance, a fimbriate suspension of Salmonella typhimurium that was to be used in tests demonstrating its inagglutinability by $E$. coli fimbrial antiserum was shown in parallel tests to be readily agglutinable by a pure fimbrial antiserum to $S$. typhimurium or a crude fimbrial antiserum to $S$. cubana.

Auto-agglutinability. Although fimbriate bacteria adhere to one another when growing in a pellicle on the surface of broth, they are generally free from the tendency to auto-agglutinate when suspended in broth or saline. Some salmonellae, however, give fimbriate-phase cultures that are weakly or strongly auto-agglutinable. It was necessary, therefore, carefully to examine the serumfree control tube in each agglutination test to confirm that the bacterial suspension was not auto-agglutinable. An additional control test was made with a non-cross-reacting serum to demonstrate that the fimbriate suspension was not agglutinable by non-specific proteins or other non-antibody substances in serum. For example, a fimbriate citrobacter suspension agglutinated by a fimbrial antiserum to $S$. typhimurium was shown in parallel tests not to be agglutinated by a non-fimbrial antiserum to $S$. typhimurium or a fimbrial antiserum to Sh. flexneri.

\section{Defimbriated and non-fimbriate-phase bacteria}

Confirmation that the agglutination of fimbriate bacteria by a crude or pure fimbrial antiserum depended on the interaction of fimbrial antigens with fimbrial antibodies was obtained by the demonstration in a parallel test that non-fimbriate forms of the same organism were not agglutinated by the serum. These non-fimbriate control tests were done both with flagellate and nonflagellate forms of non-fimbriate bacteria in order to exclude the possibility that either $\mathrm{H}$ - or O-antibodies were responsible for the agglutination of the fimbriate bacteria (e.g., see table I).

Defimbriated bacteria. One method of obtaining non-fimbriate bacteria for use in the control tests was by defimbriating bacteria taken from the same 48-hr broth culture as was used to prepare the fimbriate suspension. Fimbriae and flagella were removed by heating live bacteria in broth or saline at $90^{\circ}$ or $100^{\circ} \mathrm{C}$ for $30 \mathrm{~min}$. When the defimbriated bacteria were centrifuged from the fimbriae-containing broth or saline and resuspended in fresh saline they were no longer agglutinable by a fimbrial antiserum not containing homologous O-antibodies. Moderate dilutions of the antiserum precipitated with the bacteria-free supernatant fluid from the heated suspension, demonstrating that the antigens in the detached fimbriae had not been denatured by the heating. 
When fimbriate bacteria were treated with $0 \cdot 005 \mathrm{~N}-\mathrm{HCl}$ by Duncan's method for removal of their flagella, the fimbriae were unaffected. The acid-treated bacteria were still agglutinable by a fimbrial antiserum, though no longer agglutinable by a homologous $\mathrm{H}$-antiserum not containing $\mathrm{O}$ - or fimbrial antibodies (e.g., see table I).

Non-fimbriate-phase bacteria. Another method by which non-fimbriate bacteria were obtained for the control tests was by culture of the test strain under conditions giving growth in the non-fimbriate phase. All $\mathrm{fim}^{+}$strains of Salmonella, Arizona and Citrobacter gave nearly non-fimbriate growths by each of three methods of culture, (1) in plain broth for $6 \mathrm{hr}$, (2) in glucose broth for $12 \mathrm{hr}$, and (3) on an agar plate for $24 \mathrm{hr}$. These cultures contained only a small proportion, e.g., $1-5$ per cent., of fimbriate bacteria, were very weakly haemagglutinating $(\mathrm{HP}<25)$ and gave negative reactions in agglutination tests with homologous pure fimbrial antiserum (e.g., S7471F bacteria, table I). The bacteria grown for $6 \mathrm{hr}$ in broth or $12 \mathrm{hr}$ in glucose broth were richly flagellated, but those grown on plates were usually so poorly flagellated that they were inagglutinable or only weakly agglutinable by an $\mathrm{H}$-antiserum.

\section{Cross-reactions with crude fimbrial antisera}

The design of experiments demonstrating the wide distribution and sharing of fimbrial antigens in different strains and serotypes is shown in table I by the details of a few of the tests made with crude fimbrial antisera to $S$. typhimurium strain $\mathrm{S} 7471 \mathrm{~F}$ and $S$. cubana strain N7101. The results of these particular tests show that there is a sharing of fimbrial antigens between $S$. typhimurium strains S7471F and SL483, S. cubana N7101 and S. illinois N8498. Each crude fimbrial antiserum, because it contained $\mathrm{O}$ - and $\mathrm{H}$-antibodies, strongly agglutinated bacteria of the immunising strain regardless of whether they were tested in a fimbriated or non-fimbriated form. It also agglutinated bacteria of heterologous serotypes that did not share $\mathrm{O}$ - or $\mathrm{H}$-antigens with the immunising strain, but did so only when the bacteria were fimbriated. The reactions of this latter kind must be attributed to cross-reactivity of fimbrial antibodies.

In some tests a serum agglutinated the non-fimbriate form of a heterologous bacterium to low titre, e.g., $25-100$, but the much higher titre $(400-12,800)$ of its reaction with the fimbriate form showed that it contained antibodies reactive with fimbrial antigens in the bacterium. Some of the low-titre reactions were obtained because a serum was tested against non-fimbriate bacteria of a strain that shared a minor O-antigen, e.g., antigen 1 or 12 , with the immunising strain, but other such reactions were not explicable by the sharing of a known antigen.

The extent of the sharing of fimbrial antigens between different salmonellae and other enterobacteria was explored in a series of tests made with crude fimbrial antisera to $S$. typhimurium strains S7471F and S206, S. choleraesuis N5738, S. montevideo S51, S. typhi $\mathrm{N} 4446$ and $S$. cubana N7101. The results for three of the sera are given in table II in the columns headed "crude". Each serum was tested against three suspensions of each strain of bacteria: (1) a suspension of flagellate fimbriate bacteria from a 48-hr broth culture, (2) a 
suspension of flagellate non-fimbriate bacteria either from a 6-hr broth culture or from a 12-hr glucose broth culture, and (3) a suspension of poorly flagellate, non-fimbriate bacteria from an agar plate culture. The result was recorded as "+" when suspension (1) was agglutinated to high titre and suspensions (2) and (3) either were not agglutinated or were agglutinated only to low titre.

\section{TABLE III}

Agglutination of fimbriate bacteria of 20 strains of salmonellae and 14 strains of other enterobacteria by fimbrial antisera to Shigella flexneri, Escherichia coli and Klebsiella aerogenes

\begin{tabular}{|c|c|c|c|c|c|}
\hline \multicolumn{2}{|c|}{$\begin{array}{c}\text { Fimbriate bacteria tested for } \\
\text { agglutination }\end{array}$} & \multicolumn{4}{|c|}{$\begin{array}{l}\text { Agglutination titre* in test of bacteria with crude } \\
\text { or pure fimbrial antiserum to: }\end{array}$} \\
\hline Species and serotype & Strain & $\begin{array}{l}\text { Sh. flexneri } \\
\text { N8192 } \\
\text { (pure) }\end{array}$ & $\begin{array}{c}\text { E. coli } \\
\text { A93 } \\
\text { (pure) }\end{array}$ & $\begin{array}{c}\text { K. aerogenes } \\
\text { N9499 } \\
\text { (crude) }\end{array}$ & $\begin{array}{c}\text { K. aerogenes } \\
\text { A3 } \\
\text { (crude) }\end{array}$ \\
\hline $\begin{array}{l}\text { Salmonellae, } 20 \text { serotypes } \\
\text { A. arizonae } \\
\text { A. arizonae } \\
\text { C. ballerupensis } \\
\text { C. freundii } \\
\text { Sh. flexneri type } 1 \mathrm{a} \\
\text { E. coli type } 09 \\
\text { E. coli type } 086 \\
\text { E. coli type } \mathrm{O} \text { ? } \\
\text { K. aerogenes type } 1 \\
\text { K. aerogenes type } 2 \\
\text { K. aerogenes type } 54 \\
\text { K. aerogenes type } 55 \\
\text { Ent. cloacae } \\
\text { Ent. cloacae }\end{array}$ & $\begin{array}{l}\text { Each of } 20 \dagger \\
\text { N7296 } \\
\text { N7311 } \\
\text { N7829 } \\
\text { N6269 } \\
\text { N8192 } \\
\text { A93 } \\
\text { A108 } \\
\text { A122 } \\
\text { N9499 } \\
\text { N9621 } \\
\text { A3 } \\
\text { K55 } \\
\text { C035 } \\
\text { C793 }\end{array}$ & $\begin{array}{r}\mathrm{N}+ \\
\mathrm{N} \\
\mathrm{N} \\
\mathrm{N} \\
\mathrm{N} \\
12,800 \\
3200 \\
3200 \\
3200 \\
800 \\
400 \\
200 \\
400 \\
\mathrm{~N} \\
\mathrm{~N}\end{array}$ & $\begin{array}{r}\mathbf{N} \\
\mathbf{N} \\
\mathbf{N} \\
\mathbf{N} \\
\mathbf{N} \\
51,200 \\
51,200 \\
6400 \\
6400 \\
12,800 \\
6400 \\
3200 \\
6400 \\
\mathbf{N} \\
\mathbf{N}\end{array}$ & $\begin{array}{c}\mathrm{N} \\
\mathrm{N} \\
\mathrm{N} \\
\mathrm{N} \\
50 \\
(1600) \\
1600 \\
1600 \\
400 \\
(6400) \\
3200 \\
1600 \\
1600 \\
\mathrm{~N} \\
\mathrm{~N}\end{array}$ & $\begin{array}{c}\mathbf{N} \\
\mathbf{N} \\
\mathbf{N} \\
\mathbf{N} \\
(50) \\
800 \\
400 \\
400 \\
200 \\
1600 \\
800 \\
(1600) \\
400 \\
\mathbf{N} \\
\mathbf{N}\end{array}$ \\
\hline
\end{tabular}

* Titres in italics indicate tests in which the agglutination at optimal dilutions of serum was heavy and coarsely granular; in the other tests the agglutination was only finely granular. No agglutination was obtained in control tests with non-fimbriate-phase bacteria of the same strains, except in the four tests indicated by the titres in brackets.

$\dagger$ Each of the four sera gave negative reactions with a strain (table II) of each of the following serotypes: S. kisangani, S. paratyphi B (N8390), S. typhimurium (S7471F), S. choleraesuis (N5738), S. montevideo (N5747), S. oranienburg, S. newport, S. typhi (N4446), S. enteritidis (N4444), S. butantan, $S$. illinois, S. cubana, S. onderstepoort, S. hvittingfoss, S. minnesota, S. adelaide, S. mgulani, $S$. waycross, $S$. deversoir and $S$. humber.

$\ddagger \mathbf{N}=$ No agglutination in any dilution of serum. The lowest dilution tested was 1 in 25 .

The results show that a common fimbrial antigen was present in every tested strain of Salmonella (67 strains in 62 serotypes), Arizona (2 strains) and Citrobacter (1 strain of $C$. ballerupensis and 1 of $C$. freundii). This antigen was not shared by the other genera of enterobacteria. The crude fimbrial antisera to $S$. typhimurium, $S$. typhi and $S$. cubana did not agglutinate fimbriate bacteria of $S h$. flexneri (1 strain), E. coli (3 strains in the 3 major fimbrial-antigen groups distinguished by Gillies and Duguid), K. aerogenes (4 strains in different capsule serotypes) and Ent. cloacae (2 strains).

The results of similar tests made with crude fimbrial antisera to two strains of $K$. aerogenes are given in table III. They show that the two klebsiellae shared 
fimbrial antigens with two other strains of klebsiella, with Sh. flexneri and E. coli, but not with salmonellae in any of 20 serotypes tested, or with Arizona, $C$. ballerupensis or Ent. cloacae. The results with $C$. freundii were equivocal.

\section{Cross-reactions with pure fimbrial antisera}

Pure fimbrial antisera agglutinated fimbriate bacteria of homologous and heterologous serotypes, but did not agglutinate non-fimbriate forms of the same bacteria. Typical results, as obtained with $S$. typhimurium S7471F pure fimbrial antiserum, are shown in table I. These sera were convenient reagents for detecting the presence of shared fimbrial antigens in different bacteria. The results of tests made on a wide range of bacteria with pure fimbrial antisera to $S$. typhimurium, $S$. typhi and $S$. cubana are given in table II. The sera agglutinated to moderate or high titre $(200-12,800)$ the fimbriate bacteria of every tested strain of Salmonella (75 strains in 67 serotypes), Arizona and Citrobacter, but did not agglutinate non-fimbriate bacteria of the same strains taken from 6-hr broths, 12-hr glucose broths, 24-hr plates or heated $48-\mathrm{hr}$ broths. The $S$. typhimurium and $S$. typhi sera did not agglutinate bacteria from $48-\mathrm{hr}$ broth cultures of four genotypically non-fimbriate strains of $S$. typhimurium, including strain $S 7471 \mathrm{~N}$, but they did agglutinate fimbriate bacteria derived from these strains by transduction with phage P22.

A further 22 pure fimbrial antisera were prepared against the following strains: $S$. aberdeen S222, S. anatum S15, S. choleraesuis N5738 and S215, S. enteritidis $\mathrm{N} 4444$ and S204, S. hvittingfoss S201, S. montevideo S51, S. newport S202, $S$. paratyphi $A$ S25, S. paratyphi B S543, S. paratyphi $C$ N96, $S$. poona S205, S. potsdam S210, S. saintpaul S209, S. senftenberg S218, S. stanley S53, S. typhi N6029, S. typhimurium S206 and S207, S. worthington S45 and $A$. arizonae N7296. Each serum was tested against the fimbriate bacteria of between 6 and 24 serotypes of salmonellae and was found to agglutinate each serotype to a moderate or high titre. Taken together, the results for the crude and pure fimbrial antisera showed that a common fimbrial antigen was present in all of 95 fimbriate strains tested in 79 serotypes of Salmonella.

Pure fimbrial antisera to Sh. flexneri strain N8192 and E. coli strain A93 agglutinated fimbriate bacteria of all the strains of Sh. flexneri, E. coli and $K$. aerogenes, but not those of 20 serotypes of Salmonella and two strains each of Arizona, Citrobacter and Ent. cloacae (table III).

\section{Crude non-fimbrial antiserum}

Antiserum raised to the genotypically non-fimbriate strain $\mathrm{S} 7471 \mathrm{~N}$ of S. typhimurium contained a high titre (3200) of O-agglutinins to that organism and a very high titre $(51,200)$ of $\mathrm{H}$-agglutinins to each of its flagellar phases (table I). It was tested against fimbriate bacteria of 15 serotypes of salmonellae that did not share O- or H-antigens with S. typhimurium and, even at the low dilution of 1 in 25 , it did not agglutinate 14 of the serotypes. It agglutinated the fimbriate bacteria of the fifteenth serotype, which was $S$. minnesota, to a 
titre of 50 , but since it also agglutinated the non-fimbriate bacteria of this and other serotypes that contain $\mathrm{H}$-antigen $\mathrm{b}$, the reaction was attributed to its containing a small amount of antibody for $\mathrm{H}$-antigen $\mathrm{b}$. The demonstration that the serum did not contain any fimbrial antibody shows that the nonfimbriate bacteria of strain $\mathrm{S} 7471 \mathrm{~N}$ did not contain any fimbrial antigen, even in an occluded site.

\section{Absorption of fimbrial agglutinins}

Although the cross-agglutinations observed between fimbrial antisera and heterologous fimbriate bacteria suggested that all fimbriate salmonellae possessed a common fimbrial antigen, the results of absorption tests showed that many serotypes were distinguished by the possession of different additional fimbrial antigens. In one experiment separate samples of a pure fimbrial antiserum to $S$. typhimurium strain S206 were absorbed with fimbriate bacteria of this strain, strains of 25 other serotypes of Salmonella and strain N7296 of A. arizonae. Each absorbed sample was tested for residual agglutinating activity against fimbriate bacteria of each of the absorbing strains. It was found that all the absorbed samples had lost their agglutinating activity for nine of the strains, including S. saintpaul S209, S. montevideo S51, S. typhi N6029 and $A$. arizonae N7296, and it was concluded that all 27 absorbing strains contained a common fimbrial antigen (F1), which was probably the only fimbrial antigen present in the nine strains for which all activity was lost. The other 18 strains were still strongly agglutinated by the samples of serum absorbed with any of these nine strains. They appeared to contain and share an additional fimbrial antigen (F2), since the samples absorbed with them lost all activity for 14 of their number, including $S$. hessarek S217, S. choleraesuis S215, S. enteritidis S204 and S. cubana N7101. The remaining four strains, S. typhimurium S206, S. paratyphi B S543, S. heidelberg S213 and S. stanley S53, were agglutinated by all the absorbed sera except those absorbed by one of themselves, and therefore appeared to contain also a third fimbrial antigen (F3).

Absorption experiments with sera to other strains gave results comparable to those for the S206 serum and revealed the presence of further different fimbrial antigens. The detailed results of many of the experiments have been described by Campbell (1961).

Although differences in the content of fimbrial antigens were demonstrated between different groups of serotypes, no such difference was found between different strains in the same serotype. The fimbrial antigens appeared to be identical in eight strains of S. typhimurium: N74, N3048 (phage-type 4), N4787 (phage-type 9), N5715 (phage-type 8), S206 (phage-type 2), S207 (phagetype 3), S229 (phage-type 2) and S7471F (phage untypable). Each of these strains absorbed all the fimbrial agglutinins from a pure fimbrial antiserum to strain S206. Conversely, strain S206 absorbed all the fimbrial agglutinins from pure fimbrial antisera to strains S207 and S7471F. Similar evidence was obtained to suggest that the fimbrial antigens were identical in four strains of S. enteritidis, namely N4444 (var. danysz), S54 (var. jena), S203 (var. essen) and S204 (var. chaco). 


\section{Fimbrial agglutinins in human sera}

Antibodies reactive with the fimbrial antigens of salmonellae are found in a small proportion of human sera. In 1958, in collaboration with Dr Helen A. Wright, we studied the agglutination reactions of sera from 100 patients with fever or diarrhoea in tests with fimbriate $S$. typhimurium bacteria. The sera were examined for diagnostic purposes in Widal tests against $\mathrm{O}$ - and $\mathrm{H}$ suspensions of typhoid and paratyphoid bacteria, and also against a formaldehyde-killed $\mathrm{H}$ (antigen i) suspension of $S$. typhimurium procured from a standards laboratory. Those from 13 of the patients agglutinated the $\mathrm{H}(\mathrm{i})$ suspension to a titre of 120 or higher. Since, however, these 13 sera did not agglutinate an O-suspension of $S$. typhimurium, and later samples from the patients did not show a rise in titre, and salmonellae were not found in cultures of the patients' faeces, it was concluded that the reactions with the $\mathrm{H}$ (i) suspension were "false-positive" and did not indicate the presence of infection with $S$. typhimurium. It seemed possible that fimbrial agglutinins were responsible for the anomalous reactions and three bottles of the (Hi) suspension were therefore examined with the electron microscope. Each bottle was found to contain about 75 per cent. of richly fimbriated bacteria.

The sera from two of the patients were examined in detail. Each of them agglutinated the fimbriate $\mathrm{H}$ (i) suspension to a titre of 1920, but agglutinated non-fimbriate and poorly fimbriate $\mathrm{H}$-suspensions of $S$. typhi, $S$. paratyphi $A$ and $S$. paratyphi $B$ only to low titres (30-120). Evidence that the reactions with the $\mathrm{H}$ (i) suspension were due to the presence of fimbrial agglutinins in the sera was obtained from the following observations. (1) The sera did not agglutinate $S$. typhimurium $\mathrm{H}(\mathrm{i})$ suspensions that were composed either of non-fimbriatephase bacteria taken from a 6-hr broth culture or of genotypically non-fimbriate bacteria from a 48-hr broth culture. (2) The sera agglutinated fimbriate bacteria of $S$. typhimurium and other serotypes, e.g., S. thompson and S. typhi, even after they had been deflagellated with $0.005 \mathrm{~N}-\mathrm{HCl}$. (3) The sera no longer agglutinated the fimbriate $\mathrm{H}(\mathrm{i})$ suspension after they had been absorbed with fimbriate bacteria of $S$. thompson or $S$. typhi. The two patients had received TAB vaccine between 12 and $24 \mathrm{mth}$ previously and this vaccination was probably responsible for the low-titre agglutinations of the typhoid and paratyphoid suspensions. The vaccine may have contained some fimbriate bacteria and so may have induced the production of the fimbrial antibodies.

\section{Fimbrial antigens in $T A B$ vaccines}

Three batches of vaccine obtained in 1959 were examined for their content of fimbrial antigens. They were a heat-killed phenolised TAB vaccine (Burroughs-Wellcome), an alcoholised TABC vaccine (Lister Institute) and a heat-killed merthiolate-treated TAB vaccine (Evans). Each vaccine was used to immunise one of three rabbits. Eight injections of $0.5 \mathrm{ml}$ of the vaccine were given at intervals of 3 or 4 days and the animal was bled 10 days after the last injection. The serum from each rabbit was found to contain high titres of $\mathrm{O}-$ and $\mathrm{H}$-antibodies to the typhoid and paratyphoid bacilli. These antibodies 
were removed by absorption with non-fimbriate bacteria and the absorbed sera were then shown to contain high titres (960-3840) of agglutinins that were active on fimbriate, but not on non-fimbriate bacteria of $S$. paratyphi $B$, $S$. typhimurium, $S$. worthington and other serotypes. Since each of the sera contained these fimbrial agglutinins, it was concluded that each of the vaccines contained fimbrial antigens.

\section{Discussion}

Our observations, made by methods similar to those by which Gillies and Duguid (1958) demonstrated the fimbrial antigens of Shigella flexneri and Escherichia coli, have shown that most strains of Salmonella also produce such antigens. The antigens in the type-1 fimbriae of salmonellae are distinct from the O-, H- and Vi-antigens of the Kauffmann-White scheme, but they play a major part in determining the agglutination reactions of live and formaldehydekilled bacteria from fimbriate-phase cultures. The existence of the fimbrial antigens and their distribution in different strains were most clearly revealed in the tests made with antisera from which the non-fimbrial agglutinins had been absorbed. These " pure" fimbrial antisera agglutinated the fimbriate bacteria of homologous and heterologous serotypes, but did not agglutinate defimbriated and non-fimbriate-phase bacteria of the same strains. "Crude" (unabsorbed) fimbrial antisera were useful for demonstrating the reactions of the fimbrial antigens in heterologous strains not sharing $\mathrm{O}-, \mathrm{H}-$ or Vi-antigens with the immunising strain. Like the absorbed sera, they agglutinated the fimbriate but not the non-fimbriate bacteria of such strains.

The cross-agglutinations and cross-absorptions observed between fimbrial antisera and heterologous fimbriate bacteria gave strong evidence that a common fimbrial antigen was present in all the fimbriate strains examined in 79 serotypes of Salmonella and in the few tested strains of Arizona and Citrobacter. The absorption findings showed that strains of certain serotypes were distinguished from those of other serotypes by possessing one or more different fimbrial antigens in addition to the common one, but different strains in the same serotype appeared to have identical sets of fimbrial antigens. Gillies and Duguid had found that a minor fimbrial antigen was shared by all fimbriate strains of Sh. flexneri and E. coli. Our tests with fimbrial antisera to Sh. flexneri, E. coli and Klebsiella aerogenes showed that this common flexneri-coli antigen was present also in the fimbriae of four strains of $K$. aerogenes. These sera, however, did not react with the fimbriate salmonella, arizona and citrobacter organisms, and the salmonella sera did not react with Sh. flexneri, E. coli and $K$. aerogenes.

There was thus no evidence of any sharing of fimbrial antigens between bacteria of the salmonella-arizona-citrobacter group on the one hand and those of the shigella-escherichia-klebsiella group on the other. Antigens were shared between the different genera within each of the groups, and this sharing is in keeping with currently held views on the taxonomic relations of these genera. The position of $K$. aerogenes is a possible exception. Edwards and Ewing (1962, p. 3) have placed Klebsiella along with Enterobacter and Serratia in a principal division separate from that containing Escherichia and Shigella. We 
did not find any sharing of fimbrial antigens between $K$. aerogenes and Enterobacter cloacae, but $K$. aerogenes resembles Serratia marcescens and differs from other enterobacteria by producing type-3 as well as type- 1 fimbriae (Duguid, 1959; Duguid et al., 1966). We do not yet have any information about the antigenic properties of the type-3 fimbriae. Type- 3 fimbriae were present in addition to type- 1 fimbriae in three of our four strains of $K$. aerogenes, but the reactions of these strains with the antisera to Sh. flexneri and $E$. coli must have depended on antigens in their type-1 fimbriae, since only type-1 fimbriae are present in Sh. flexneri and E. coli.

Our findings support the suggestion by Gillies and Duguid that the nonspecific "X-antigens" observed in various serotypes of salmonellae by Topley and Ayrton (1924), Happold (1928, 1929) and Cruickshank (1939) were fimbrial antigens. Fimbrial antigens resemble the $\mathrm{X}$-antigens in the following respects: (1) they are absent from young $(6 \mathrm{hr})$ cultures in aerobic static broth and from old as well as young cultures in glucose broth and anaerobic broth; (2) they appear in readily detectable amounts after about $16 \mathrm{hr}$ in aerobic static broth, and (3) they become detached from the bacteria, though not denatured, on heating at $100^{\circ} \mathrm{C}$. The Mutton strain of S. typhimurium, in which Topley and Ayrton demonstrated X-antigens, was one of the strains (N74) in which we found fimbrial antigens. On the assumption that the $\mathrm{X}$-antigens were fimbrial, the results of our absorption tests agree with Happold's observation that the X-antigens, though they included a common factor, were not identical in all salmonellae.

Misleading cross-reactions may be obtained in agglutination tests made for the identification of salmonellae if fimbriate-phase bacteria are used for preparing the agglutinable suspensions and producing the diagnostic antisera. In these circumstances an antiserum to any one serotype may agglutinate the live or formaldehyde-killed bacteria of any other serotype. Bacteriologists generally avoid obtaining such cross-reactions because they work with bacteria cultured by methods selective for the non-fimbriate phase, e.g., bacteria from cultures on agar or young cultures in broth. In our experience the surest method for obtaining richly flagellate, non-fimbriate-phase bacteria for examination in $\mathrm{H}$-agglutination tests is by culture for $6 \mathrm{hr}$ in broth from a small inoculum of bacteria taken from a colony on agar or a swarm through semi-solid agar. Poorly flagellate, non-fimbriate-phase bacteria suitable for examination in O-agglutination tests can be obtained from cultures grown for $24 \mathrm{hr}$ on welldried agar plates. Suitable O-suspensions can also be made from any kind of culture by heating the bacteria at $100^{\circ} \mathrm{C}$, since heating detaches the fimbriae as well as the flagella. The bacteria should be separated from the fluid in which they have been heated, otherwise the detached fimbriae may be precipitated by fimbrial antibody and simulate agglutinated bacteria.

Cultures grown by methods selective for the non-fimbriate phase generally contain a small proportion of fimbriate bacteria. Although these are too few to make the culture agglutinable with fimbrial antibody, they may be numerous enough to induce the production of fimbrial antibody when the culture is injected into an animal. It is therefore advantageous to choose genotypically 
non-fimbriate strains of bacteria as immunising strains for the production of diagnostic antisera. Such strains are available in the more important salmonella serotypes (Duguid et al., 1966).

Our finding of human sera that contained salmonella fimbrial agglutinins and gave "false-positive" reactions in Widal tests made with a fimbriate bacterial suspension emphasises the importance of using only non-fimbriate bacteria to prepare the Widal suspensions. A "false-positive" reaction probably attributable to fimbrial agglutinins was reported by Cruickshank in 1939. The serum from a patient with an obscure illness later diagnosed as brucellosis strongly agglutinated an alcoholised O-suspension of $S$. paratyphi $B$. Cruickshank showed that this reaction was due to the presence of X-antigens in the suspension and $\mathrm{X}$-agglutinins in the serum. He later demonstrated that $\mathrm{X}$-agglutinins were present in a small proportion of normal human sera (titres $>20$ in 25 per cent. and $>80$ in 2.5 per cent.) and sera from typhoid and paratyphoid-B fevers (titres $>20$ in 19 per cent. and $>80$ in 9.5 per cent.). Our finding that 13 out of 100 human sera submitted for Widal test contained salmonella fimbrial agglutinins to a titre of 120 or higher is comparable to these findings of Cruickshank. It is to be contrasted with the finding by Gillies and Duguid that 80 out of 81 normal human sera contained fimbrial agglutinins to Sh. flexneri and E. coli.

The production of X- or fimbrial agglutinins in man may be the result of vaccination with a TAB vaccine containing fimbrial antigens. Cruickshank observed twelve persons given two doses of vaccine and found that five of them developed X-agglutinins to titres of 20-160. We found that each of three types of typhoid-paratyphoid vaccine induced the production of high titres of fimbrial agglutinins in rabbits. Whether the fimbrial antibodies have any protective action is still unknown. Cefalù and Comes (1965) found that Sh. flexneri and $S$. typhi fimbrial antisera from which the O-antibodies had been absorbed still retained some bactericidal activity for the homologous bacteria, and they attributed this activity to the fimbrial antibodies. Campbell (1961) and Bhagwan Singh (1966), on the other hand, did not find that vaccines containing fimbriate bacteria were significantly more effective in protecting mice against oral or intraperitoneal challenge with virulent fimbriate $S$. typhimurium bacteria than vaccines containing only non-fimbriate bacteria.

\section{SUMMARY}

Antigens that determine agglutination reactions, and are distinct from the $\mathrm{O}-, \mathrm{H}-$ and Vi-antigens, were demonstrated in the type- 1 fimbriae of bacteria in fimbriate-phase cultures of salmonellae. Most strains of salmonellae produced fimbriate cultures when grown for a sufficient period, e.g., $24-48 \mathrm{hr}$, at $37^{\circ} \mathrm{C}$ in aerobic static broth. The same strains produced non-fimbriate-phase cultures lacking fimbrial antigens when grown for only $6 \mathrm{hr}$ in broth, for $12 \mathrm{hr}$ in glucose broth or for $24 \mathrm{hr}$ on an agar plate. The independence of the fimbrial antigens from the O-, $\mathrm{H}-$ and $\mathrm{Vi}$-antigens was shown by the finding that an antiserum raised against a fimbriate-phase culture and freed from $\mathrm{O}-, \mathrm{H}-$ and 
other non-fimbrial agglutinins by absorption with non-fimbriate-phase bacteria ("pure fimbrial antiserum") strongly agglutinated fimbriate-phase bacteria, but did not agglutinate either non-fimbriate-phase bacteria or fimbriate bacteria that had been defimbriated by heating at $100^{\circ} \mathrm{C}$.

Crude (unabsorbed) and pure (absorbed) fimbrial antisera to strains of several salmonella serotypes agglutinated fimbriate-phase bacteria of a wide variety of heterologous serotypes. The reactions indicated the presence of a common fimbrial antigen in all of 95 fimbriate strains in 79 serotypes of Salmonella and two strains each of Arizona and Citrobacter. Absorption findings suggested that other fimbrial antigens were present in addition to the common one in strains of certain serotypes, but that the same antigens were present in different strains of the same serotype. A common fimbrial antigen was demonstrated in strains of Shigella flexneri, Escherichia coli and Klebsiella aerogenes, but there was no sharing of antigens between this group of bacteria and the salmonella-arizona-citrobacter group.

Misleading cross-reactions may be obtained in diagnostic agglutination tests unless only non-fimbriate bacteria are used for the preparation of agglutinable suspensions and the production of diagnostic antisera. The development of cross-reacting fimbrial agglutinins in persons who have been infected with a salmonella or immunised with a TAB vaccine containing fimbrial antigens may lead to false-positive reactions being obtained in Widal tests.

We wish to express our appreciation of the help given to us by Drs E. S. Anderson, G. N. Cooper, P. R. Edwards, F. Kauffmann, S. P. Lapage, B. Rowe, B. A. D. Stocker, Joan Taylor and Helen A. Wright, who supplied strains and provided information about their antigens.

\section{REFERENCES}

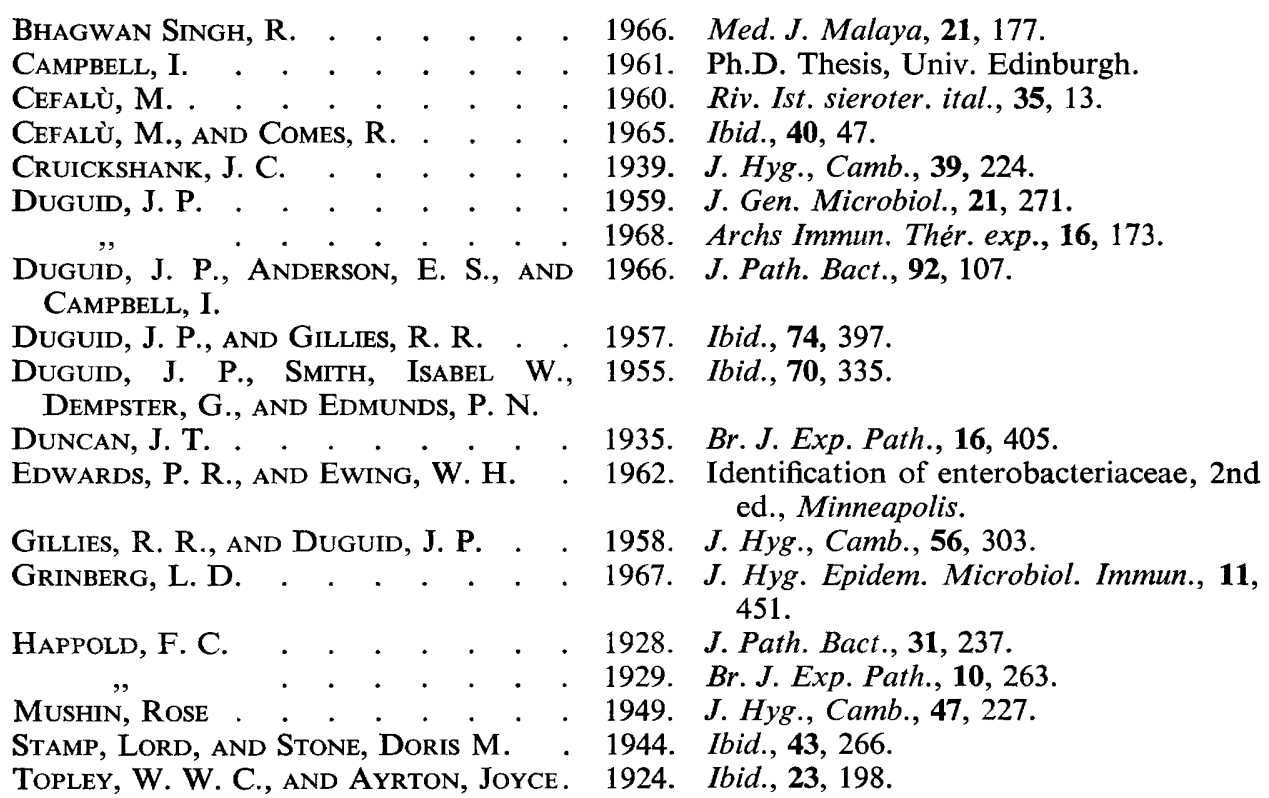

